\title{
A HGH-RESOLUTION CATALOG OF COMETARY EMISSION LINES
}

\author{
M. E. Brown ${ }^{1}$ \\ Division of Geological and Planetary Sciences, Caltech, Pasadena, California 91125 \\ Electronic mail: mbrown@kepler.gps.caltech.edu \\ A. H. BOUCHEZ \\ Lunar and Planetary Laboratory, University of Arizona, Tucson, Arizona 85721 \\ Electronic mail: antonin@bigz.berkeley.edu

\section{H. SPINRAD} \\ Department of Astronomy, University of California at Berkeley, Berkeley, California 94720 \\ Electronic mail: spinrad@bigz.berkeley.edu

\section{M. JOHNS-KRULL} \\ McDonald Observatory, University of Texas at Austin, Austin, Texas \\ Electronic mail: cmj@antaeus.as.utexas.edu \\ Received 1996 April 19; revised 1996 June 18
}

\begin{abstract}
Using high-resolution spectra obtained with the Hamilton echelle spectrograph at Lick Observatory, we have constructed a catalog of emission lines observed in comets Swift-Tuttle and Brorsen-Metcalf. The spectra cover the range between $3800 \AA$ and $9900 \AA$ with a spectral resolution of $\lambda / \Delta \lambda \sim 42000$. In the spectra, we catalog 2997 emission lines of which we identify 2438 . We find cometary lines due to $\mathrm{H}, \mathrm{O}, \mathrm{C}_{2}$, $\mathrm{CN}, \mathrm{NH}_{2}, \mathrm{C}_{3}, \mathrm{H}_{2} \mathrm{O}^{+}, \mathrm{CH}$, and $\mathrm{CH}^{+}$. We list 559 unidentified lines compiled from the two spectra and comment on possibilities for their origins. (C) 1996 American Astronomical Society.
\end{abstract}

\section{INTRODUCTION}

Comets are thought to be the least modified remnant from the creation of the solar system, and an understanding of their composition can provide insight into the conditions in the early solar system and into the region of cometary formation (Spinrad 1987). Spectroscopy of the comae provides the only means of determining cometary composition from the Earth, and a substantial effort in recent years has focused on the observation and identification of new molecular species in comets. While most of the current effort concentrates on the infrared and longer wavelengths, the visible region of the spectrum remains incompletely explored.

Low resolution visible spectra are now routinely obtained for many comets (Newburn \& Spinrad 1989; Cochran et al. 1992; Hicks \& Fink 1996), showing the well-known bands of $\mathrm{CN}, \mathrm{C}_{3}, \mathrm{C}_{2}$, and $\mathrm{NH}_{2}$. At higher resolution $(\lambda / \delta \lambda \sim 40000-100000)$, studies have had to concentrate on small regions of the visible spectrum: resolving individual bands to measure the band structure (Tegler \& Wyckoff 1989; O'Dell et al. 1988), separating isotopic components (Kleine et al. 1995), and measuring the kinematics of hydrogen (Brown \& Spinrad 1993; Magee-Sauer et al. 1990) and ionized water (Brown 1993; Scherb et al. 1990). Such spectra of small targeted regions of the visible spectrum are unlikely to detect previously unknown emissions.
With the advent of echelle spectrographs, we can now simultaneously record a spectrum at high resolution with continuous coverage in the visible region. In this paper, we report results of echelle spectroscopy of of two bright comets and discuss our findings of identified and unidentified lines.

\section{OBSERVATION AND DATA REDUCTION}

The two comets were observed at Lick Observatory using the Hamilton echelle spectrograph (Vogt 1989). Comet Brorsen-Metcalf (23P/1989 N1) was observed on $1989 \mathrm{Au}-$ gust 22 using the 3-m Shane telescope, while Comet SwiftTuttle (109P/1992 S2) was observed on 1992 November 18 using the $0.6-\mathrm{m}$ coudé auxiliary telescope. The observational circumstances are summarized in Table 1.

The exposures were obtained by centering the image of the comet on the slit and hand-guiding on the cometary motion. The Swift-Tuttle spectrum was recorded on a $2400^{2}$ Ford CCD which is large enough to simultaneously record all 92 spectral orders, providing uninterrupted wavelength coverage from $3800 \AA$ to $8700 \AA$, and partial coverage to $9900 \AA$. Binning of the CCD in the spectral dimension caused a slight undersampling of the resolution of the spectrograph. The Brorsen-Metcalf spectrum was recorded on a smaller $800^{2}$ TI CCD, which recorded 41 partial spectral orders, giving partial wavelength coverage from 4000 to $5500 \AA$.

For each spectrum, flat-fielding of the multi-order two-

${ }^{1}$ Hubble Fellow. 


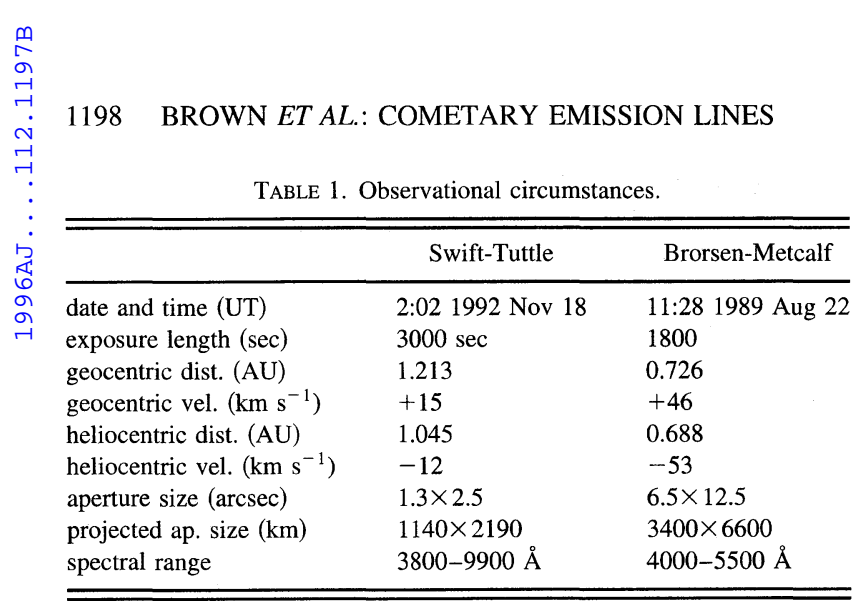

dimensional spectrum was accomplished by dividing by a long-slit quartz lamp spectrum taken the same night. The exact order locations of each spectrum were determined by a deckered quartz lamp spectrum, also taken the same night. A 3-pixel-wide swath around each of these order locations was then extracted to produce a one-dimensional spectrum of each order. The echelle blaze function was removed by dividing each order by the average one-dimensional order profile of the quartz spectrum. The wavelength scale was determined from a fit to the spectrum of a thorium-argon lamp with a high density of known emission lines. Sample sections of the reduced one-dimensional spectra of comets Swift-Tuttle and Brorsen-Metcalf are shown in Fig. 1.

For each comet, every significant peak in the onedimensional spectrum was checked against the twodimensional echelle image to distinguish between real lines and apparent lines due to radiation events and CCD defects. In this manner, we found 2997 emission lines in the comets. We determined the wavelength of each emission line with a second order polynomial fit to the line core, which gave a typical accuracy of $\pm \sim 0.05 \AA$. Emission lines from the sky, primarily due to $\mathrm{OH}$, were identified and removed using the tabulation of Osterbrock et al. (1996).

\section{LINE IDENTIFICATION}

Many of the 2997 emission lines fall in well known molecular bands. We compared the line positions and intensities to positions and intensities from laboratory spectra of all species known to have cometary emissions in the visible wavelength region [based on the compilations of Arpigny (1994) and Festou et al. (1993)]. In attempting to identify the lines, both wavelength and relative intensity have been taken into account; molecular lines have been identified only if several transitions in a particular band are present, at the correct wavelength and relative intensity. A total of 2438 lines were identified with known cometary emitters in this manner.

An attempt was made to identify the remaining 559 lines. We compiled a list of laboratory wavelengths of many molecules with visible emissions which could plausibly be contributors. Table 2 lists all of the molecules for whose emissions we searched and the references to the laboratory spectra. No new species were identified.

Table 3 list all of the lines found in comets Swift-Tuttle and Brorsen-Metcalfe and their identifications, if known. This table, along with separate tables for each identified mol-
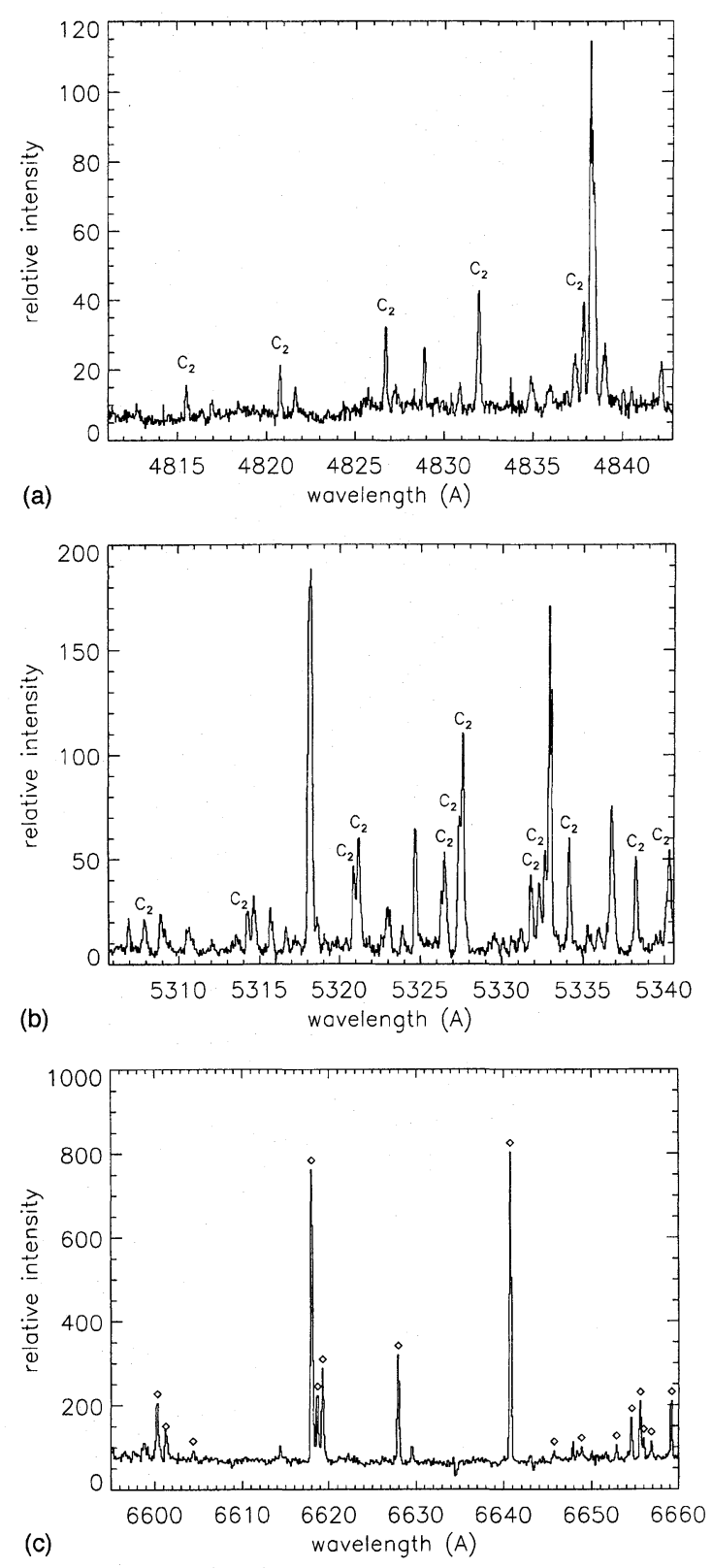

FIG. 1. Sample regions of high resolution comet spectra. (a) A region showing the unidentified lines near $4838 \AA$ and a small part of the $\mathrm{C}_{2}(0,0)$ band. (b) A region showing the strong unidentified lines near $5320 \AA$ and part of the $\mathrm{C}_{2}(0,1)$ band. (c) A region of strong $\mathrm{NH}_{2}$ lines. All lines marked with a diamond are members of the $\mathrm{NH}_{2}(0,7,0)$ band.

cule and for the unidentified lines, can be accessed in electronic form at http: / ptolemy.gps. caltech.edu/ $\sim$ mbrown/comet/echelle.html via an internet browser. In the table, column (1) lists the wavelength at which the line was measured in the spectrum of comet SwiftTuttle. A " + " ' in this column indicates that the line with the wavelength listed in the previous row has been identified as a blend of two or more lines, with the laboratory wavelengths and identifications given in the subsequent rows. Column (2) gives the relative intensity of the emission line, with the brightest detected line equal to 1000 . These intensi- 
TABLE 2. Laboratory spectra references.

\begin{tabular}{|c|c|c|c|}
\hline Molecule & Reference & Molecule & Reference \\
\hline $\mathrm{C}_{2}$ & Phillips \& Davis (1968) & $\mathrm{H}_{3}$ & Dabrowski and Herzberg (1980) \\
\hline \multirow{4}{*}{$\mathrm{C}_{3}$} & Merer (1967) & & Herzberg \& Watson (1980) \\
\hline & Kiess and Bass (1954) & & Herzberg et al. 1982 \\
\hline & Douglas (1951) & HNO & Dixon and Rosser (1985) \\
\hline & Clusius and Douglas (1954) & HSO & Kakimoto et al. 1980 \\
\hline \multirow[t]{2}{*}{$\mathrm{CN}$} & Davis and Phillips (1968) & $\mathrm{HCNO}$ & Noble et al. (1984) \\
\hline & Jevons (1926) & $\mathrm{H}_{2} \mathrm{CS}$ & Judge \& King (1979) \\
\hline \multirow[t]{3}{*}{$\mathrm{CH}$} & Gerö (1941) & $\mathrm{H}_{2} \mathrm{CCS}$ & Cloutheir (1987) \\
\hline & Kiess \& Broida (1956) & $\mathrm{NH}$ & Lunt et al. (1935) \\
\hline & Moore \& Broida (1959) & & Judge \& Moule (1980) \\
\hline $\mathrm{CH}^{+}$ & Douglas \& Herzberg (1942) & & Suzuki et al. (1983) \\
\hline \multirow[t]{4}{*}{$\mathrm{NH}_{2}$} & Dressler \& Ramsay (1959) & $\mathrm{OH}$ & Dejardin et al. (1953) \\
\hline & Ross et al. 1988 & & Dieke \& Crosswhite (1962) \\
\hline & Dixon et al. (1991) & & \\
\hline & Arpigny (1995) & $\mathrm{S}_{2}$ & Naudé (1945) \\
\hline $\mathrm{H}_{2} \mathrm{O}^{+}$ & Lew (1976) & SiN & Bredohl et al. (1976) \\
\hline \multirow{3}{*}{$\mathrm{CO}$} & Coster \& Brons (1934) & $\mathrm{SiO}$ & Verma \& Mulliken (1961) \\
\hline & von Schmid and Gerö (1935) & $\mathrm{SiH}_{2}$ & Dubois (1968) \\
\hline & Johnson \& Asundi (1929) & $\mathrm{CO}^{+}$ & Coster et al. (1932) \\
\hline $\mathrm{CCO}$ & Devillers \& Ramsay (1971) & & Rao (1950) \\
\hline $\mathrm{CCN}$ & Kakimoto \& Kasuya (1982) & $\mathrm{CS}_{2}^{+}$ & Balfour (1976) \\
\hline $\mathrm{CH}_{2}$ & Petek et al. (1987) & $\mathrm{H}_{2} \mathrm{~S}^{+}$ & Duxbury et al. (1972) \\
\hline $\mathrm{CNO}$ & Ramsay \& Winnewisser (1983) & $\mathrm{H}_{2} \mathrm{CCOH}^{-}$ & Mead et al. (1984) \\
\hline $\mathrm{C}_{2} \mathrm{H}_{3} \mathrm{O}$ & Inoue \& Akimoto (1981) & $\mathrm{N}_{2}^{+}$ & Douglas (1953) \\
\hline \multirow{2}{*}{$\mathrm{HCO}$} & Herzberg \& Ramsay (1955) & $\mathrm{N}_{2} \mathrm{O}^{+}$ & Aarts \& Callomon (1987) \\
\hline & & $\mathrm{OH}^{+}$ & Weniger \& Herman (1958) \\
\hline
\end{tabular}

TABLE 3. Sample of the catalog of emission lines.*

\begin{tabular}{|c|c|c|c|c|c|c|c|}
\hline$\lambda, \mathrm{ST}$ & $I, \mathrm{ST}$ & $\lambda, \mathrm{BM}$ & $I, \mathrm{BM}$ & $\lambda$, lab & Species & Band & Transition \\
\hline & & 4361.71 & 13 & 4361.77 & $\mathrm{C}_{2}$ & $(3,1)$ & $R_{2}(03)$ \\
\hline 4364.51 & 25 & & & 4364.50 & $\mathrm{C}_{2}$ & $(4,2)$ & $P_{1}(29)+P_{2}(28)+P_{3}(27)$ \\
\hline 4364.66 & 22 & & & 4364.70 & $\mathrm{C}_{2}$ & $(4,2)$ & $P_{1}(22)+P_{1}(26)+P_{2}(26)+P_{3}(18)$ \\
\hline 4364.80 & 20 & & & 4364.78 & $\mathrm{C}_{2}$ & $(4,2)$ & $P_{1}(23)+P_{2}(24)+P_{3}(19)$ \\
\hline 4364.99 & 21 & & & 4364.94 & $\mathrm{C}_{2}$ & $(4,2)$ & Bandhead \\
\hline \multirow[t]{5}{*}{4371.26} & 16 & 4371.26 & 20 & 4371.44 & $\mathrm{C}_{2}$ & $(3,1)$ & Bandhead \\
\hline & & 4381.48 & 15 & 4381.41 & $\mathrm{C}_{2}$ & $(2,0)$ & $P_{1}(15)$ \\
\hline & & + & & 4381.52 & $\mathrm{C}_{2}$ & $(2,0)$ & $P_{1}(27)+P_{3}(26)$ \\
\hline & & + & & 4381.44 & $\mathrm{C}_{2}$ & $(2,0)$ & $P_{1}(16)+P_{2}(27)$ \\
\hline & & + & & 4381.41 & $\mathrm{C}_{2}$ & $(2,0)$ & $P_{1}(28)+P_{3}(13)$ \\
\hline 4381.70 & 15 & & & 4381.72 & $\mathrm{C}_{2}$ & $(2,0)$ & $P_{1}(26)$ \\
\hline 4381.96 & 17 & 4381.90 & 24 & 4382.15 & $\mathrm{C}_{2}$ & $(2,0)$ & Bandhead \\
\hline \multirow[t]{3}{*}{4428.45} & 9 & 4428.45 & 20 & & unid & & \\
\hline & & 4439.88 & 11 & & unid & & \\
\hline & & 4452.20 & 10 & & unid & & \\
\hline 4510.99 & 17 & 4510.99 & 14 & 4511.00 & $\mathrm{NH}_{2}$ & $(0,15,0)$ & $3_{03}-3_{13}$ \\
\hline+ & & + & & 4511.14 & $\mathrm{NH}_{2}$ & $(0,15,0)$ & $2_{02}-2_{12}$ \\
\hline \multirow[t]{3}{*}{4515.57} & 17 & 4515.59 & 14 & 4515.59 & $\mathrm{C}_{2}$ & $(1,0)$ & $R_{1}(87)+R_{2}(86)+R_{3}(85)$ \\
\hline & & 4516.87 & 10 & & unid & & \\
\hline & & 4519.14 & 9 & & unid & & \\
\hline \multirow[t]{2}{*}{4519.59} & 16 & 4519.69 & 10 & 4519.69 & $\mathrm{C}_{2}$ & $(1,0)$ & $R_{1}(86)+R_{2}(85)+R_{3}(84)$ \\
\hline & & 4520.10 & 10 & & unid & & \\
\hline \multirow[t]{5}{*}{4521.45} & 20 & 4521.41 & 18 & 4521.41 & $\mathrm{NH}_{2}$ & $(0,15,0)$ & $1_{01}-2_{11}$ \\
\hline & & 4521.55 & 16 & & unid & & \\
\hline & & 4521.75 & 11 & & unid & & \\
\hline & & 4522.13 & 9 & & unid & & \\
\hline & & 4523.20 & 9 & 4523.15 & $\mathrm{C}_{2}$ & $(1,0)$ & $R_{1}(85)+R_{2}(84)+R_{3}(83)$ \\
\hline \multirow[t]{2}{*}{4523.74} & 19 & 4523.70 & 13 & 4523.42 & $\mathrm{C}_{2}$ & $(2,1)$ & $R_{1}(82)+R_{2}(81)+R_{3}(80)$ \\
\hline & & 4525.12 & 12 & & unid & & \\
\hline 4526.90 & 16 & 4526.79 & 13 & 4526.80 & $\mathrm{C}_{2}$ & $(2,1)$ & $R_{1}(81)+R_{2}(80)+R_{3}(79)$ \\
\hline \multirow[t]{5}{*}{4527.28} & 16 & 4527.24 & 11 & 4527.20 & $\mathrm{C}_{2}$ & $(1,0)$ & $R_{1}(84)+R_{2}(83)+R_{3}(82)$ \\
\hline & & 4527.73 & 11 & & unid & & \\
\hline & & 4530.58 & 11 & 4530.63 & $\mathrm{C}_{2}$ & $(1,0)$ & $R_{1}(83)+R_{2}(82)+R_{3}(81)$ \\
\hline & & + & & 4530.30 & $\mathrm{C}_{2}$ & $(2,1)$ & $R_{1}(80)+R_{2}(79)+R_{3}(78)$ \\
\hline & & 4531.15 & 11 & & unid & & \\
\hline 4533.53 & 19 & 4533.56 & 10 & 4533.63 & $\mathrm{C}_{2}$ & $(2,1)$ & $R_{1}(79)+R_{2}(78)+R_{3}(77)$ \\
\hline
\end{tabular}

Table 1 can be found in AAS CD-ROM, Vol. 7, 1996. Only the first page is shown here for form and content. 

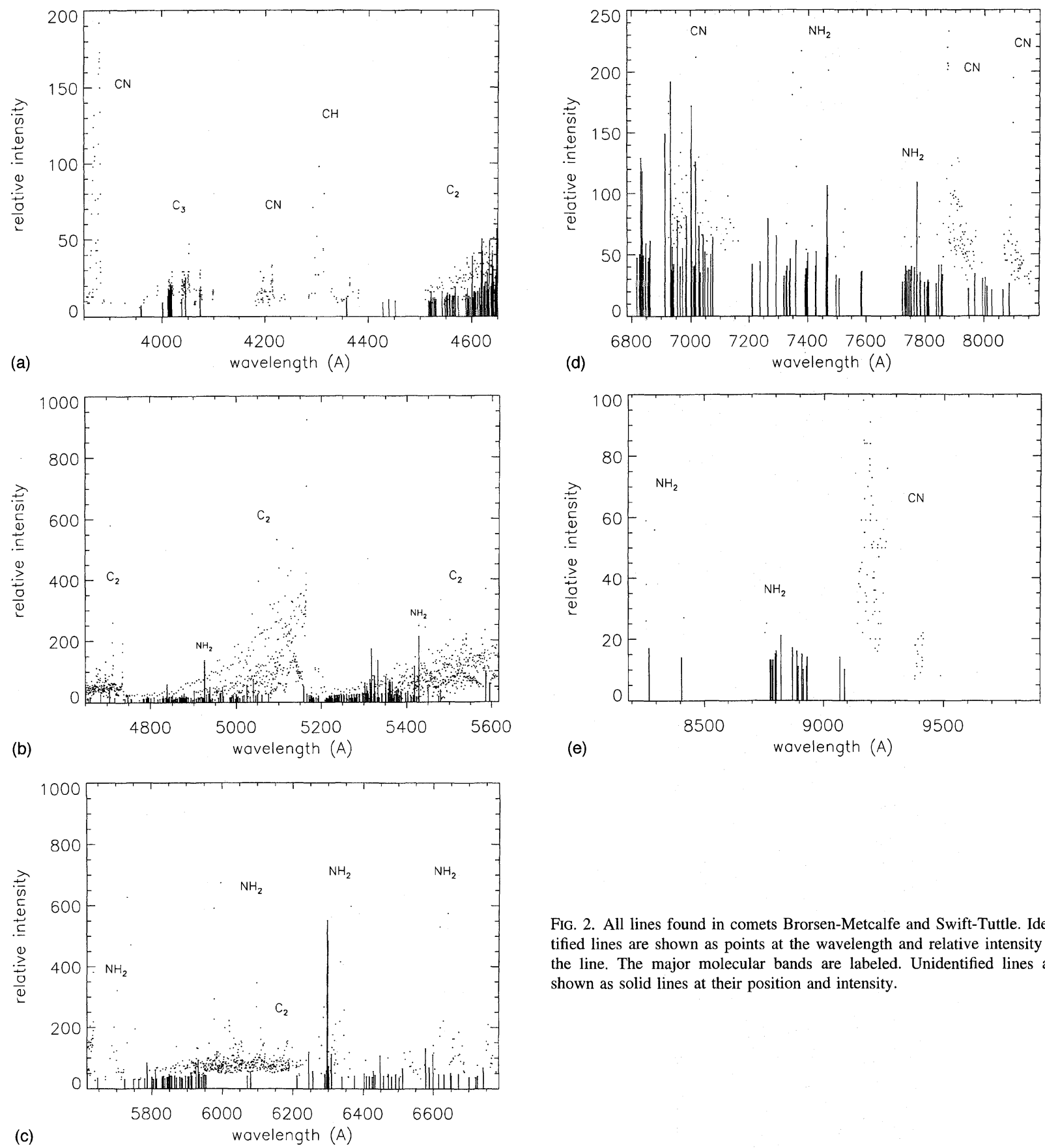

ties are corrected for the echelle blaze function, but not for CCD response or atmospheric absorption. The relative intensities are thus reliable within a spectral order but not between widely spaced orders. Columns (3) and (4) are identical to columns (1) and (2), but for comet Brorsen-Metcalf. Column (5) lists the laboratory wavelength of the given identification. Columns (6), (7), and (8) give the identified molecule, band, and transition, respectively. If the emission line is unidentified, column (6) states "unid.' Figure 2 shows, in graphical form, the wavelength and relative intensity of all cometary lines. Identified lines are shown as points, unidentified lines

are shown as complete lines, and the major identified molecular bands are indicated.

\section{UNIDENTIFIED LINES}

Shortward of the beginning of the $\mathrm{C}_{2}$ Swan band at 5600 $\AA$, most of the unidentified bands are grouped within the known molecular bands. We therefore suggest that many of these lines are unclassified lines belonging to the neighboring bands of $\mathrm{C}_{2}, \mathrm{NH}_{2}$, or $\mathrm{C}_{3}$. In this region of the spectrum, we draw attention to the complex of lines around $4838 \AA$ and 
around $5325 \AA$ (see Fig. 1), which do not appear to follow this general trend, and to the three lines at $4428.45,4439.88$, and $4452.20 \AA$, which are not particularly bright but fall well outside any known band.

The brightest of the unidentified lines occur in the $\sim 6000-7000 \AA$ region, closely associated with identified $\mathrm{NH}_{2}$ bands, and in low-resolution cometary spectra these lines are assumed to be a part of the neighboring $\mathrm{NH}_{2}$ band (e.g., Wyckoff et al. 1988). We strongly suspect that these are indeed lines of $\mathrm{NH}_{2}$ which have not been identified in the high-resolution laboratory spectra. In particular, most of the $\mathrm{NH}_{2}$ laboratory work has been on absorption spectroscopy, so many of the high-lying transitions have not been observed. Recent work on laser-induced fluorescence spectroscopy of $\mathrm{NH}_{2}$ should allow (Dixon et al. 1991) the laboratory identification of many higher angular momentum states.

Finally, several clumps of unidentified lines in the 7000$9000 \AA$ region of the spectra do not appear to be associated with any known bands. Most prominent of these is an isolated cluster between 6818 and $6863 \AA$, which may continue to $7180 \AA$ mixed with a $\mathrm{CN}$ band. Another isolated cluster around $9000 \AA$ is also unidentified.

In the future, we plan to aid the identification of unknown cometary emission lines by their spatial distribution; spectra will be obtained at many different positions in the coma of the comet, and emissions from a common species will have a common spatial distribution. In this manner, the many emission lines that are suspected to be unclassified lines of known emitters will be identified, and lines from any truly unknown emitting species will become more apparent.

\section{CONCLUSIONS}

We have cataloged a total of 2997 emission lines between $3855 \AA$ and $9567 \AA$ in comets Brorsen-Metcalfe and SwiftTuttle. Of these lines, 1595 contain contributions due to $\mathrm{C}$ 2, 371 due to $\mathrm{CN}, 303$ due to $\mathrm{NH}_{2}, 130$ due to $\mathrm{C}_{3}$, and 5 due to atomic hydrogen or oxygen. The remaining 559 lines remain unidentified even after an intensive search for new molecular species. We suggest that the majority of the unidentified lines are previously unclassified lines due to the known molecule species.

We thank C. Arpigny, S. Kim, and S. Wyckoff for useful conversations. This work was supported by NASA through grant NAGW-2883 and grant HF-1056.01-94A from the Space Telescope Science Institute, which is operated by the Association of Universities for Research in Astronomy, Inc., under NASA contract NAS5-2655.

\section{REFERENCES}

Aarts, J. F. M., \& Callomon, J. H. 1987, Mol. Phys., 62, 637

Arpigny, C. 1995, private communication

Arpigny, C. 1994, 50th International Meeting of Physical Chemistry, AIP Conference Proceedings No. 50 (AIP, New York)

Balfour, W. J. 1976, Can. J. Phys., 54, 1969

Bredohl, H., Dubois, I., Houbrechts, Y., \& Singh, M. 1976, Can. J. Phys., 54,680

Brown, M. E., Johns, C. M., \& Spinrad, H. 1993, Geophys. Res. Lett., 20, 1003

Brown, M. E., \& Spinrad, H. 1993, Icarus, 104, 197

Cloutheir, D. J. 1987, J. Phys. Chem., 91, 1354

Clusius, K., \& Douglas, A. 1954, Can. J. Phys., 32, 319

Cochran, A. L., Barker, E. S., Ramseyer, T. F., \& Storrs, A. D. 1992, Icarus, 98, 151

Coster, D., \& Brons, F. 1934, Physica 1, 634

Coster, D., Brons, H. H., \& Bulthuis, H. 1932, Z. Phys., 79, 787

Dabrowski, I., \& Herzberg, G. 1980, Can. J. Phys., 58, 1238

Davis, S. P., \& Phillips, J.G. 1968, The Red System $\left(A^{2} \Pi-X^{2} \Sigma\right)$ of the CN

Molecule (University of California Press, Berkeley)

Devillers, C., \& Ramsay, D. A. 1971, Can. J. Phys., 49, 2839

Déjardin, G., Janin, J., \& Peyron, M. 1993, Cahiers de Phys., 46, 1

Dieke, G. H., \& Crosswhite, H. M. 1962, J. Quant. Spectrosc. Radiat. Transfer, 2, 97

Dixon, R. N., Irving, S. J., Nightingale, J. R., \& Vervloet, M. 1991, J. Chem.

Soc. Faraday Trans. 87, 2121

Dixon, R. N., \& Rosser, C. A. 1985, J. Mol. Spectrosc., 110, 262

Douglas, A. E. 1953, ApJ, 117, 380

Douglas, A. E. 1951, ApJ, 114, 466

Douglas, A. E., \& Hertzberg, G. 1942, Can. J. Res., 20 A, 1

Dressler, K., \& Ramsay, D. A. 1959, PTSRL, A251, 553

Dubois, I. 1968, Can. J. Phys., 46, 2485

Duxbury, G., Horani, M., \& Rostas, J. 1972, PTSRL A, 331, 109

Festou, M. C., Rickman, H., \& West, R. M. 1993, ARA\&A, 5, 37 Gerö, L. 1941, Z. Phys., 118, 27

Herzberg, G., Hougen, J. T., \& Watson, J. K. G. 1982, 60, 1261

Herzberg, G., \& Ramsay, D. A. 1955, PTRSL, A233, 34
Herzberg, G., \& Watson, J. K. G. 1980, Can. J. Phys., 58, 1250

Hicks, M. D., \& Fink, U. 1996, ApJ, 459, 729

Inoue, G., \& Akimoto, H. 1981, J. Chem. Phys., 74, 425

Jevons, W. 1926, PTRSL, 112, 407

Johnson, R. C., \& Asundi, R.K. 1929, PTRSL, A 123, 560

Judge, R. H., \& King, G. W. 1979, J. Mol. Spectrosc., 78, 51

Judge, R. H., \& Moule, D. C. 1980, J. Mol. Spectrosc., 81, 37

Kakimoto, M., \& Kasuya, T. 1982, J. Mol. Spectrosc., 94, 380

Kakimoto, M., Saito, S., \& Hirota, E. 1980, J. Mol Spectrosc., 80, 334

Kiess, N. H., \& Broida, H. 1956, ApJ, 123, 166

Kiess, N. H., \& Bass, A. 1954, J. Chem. Phys., 22, 569

Kleine, M., Wyckoff, S., Wehinger, P. A., \& Peterson, B. A. 1995, ApJ, 439, 1021

Kuhn, R., Maier, J. P., \& Ochsner, M. 1986, Mol. Phys., 59, 441

Lew, H. 1976, Can J. Phys., 54, 2028

Lunt, R. W., Pearse, R. W. B., \& Smith, E. C. W 1935, PTRSL, 151, 602

Magee-Sauer, K., Scherb, F., Roesler, F.P., \& Harlander, J. 1990, Icarus, 84, 154

Mead, R. D., Lykke, K. R., \& Lineberger, W. C. 1984, J. Chem. Phys., 81, 4883

Merer, A. J. 1967, Can. J. Phys., 45, 4103

Moore, C. E., \& Broida, H. 1959, J. Res. NBS, 63A, 19

Mrozowski, S. 1941, Phys. Rev., 60, 730

Naudé, S. M. 1945, South African J. Sci., 41, 128

Newburn, R. L., \& Spinrad, H. 1989, AJ, 97, 552

Noble, M., Nadler, I., Reisler, H., \& Wittig, C. 1984, J. Chem. Phys., 81, 4333

O’Dell, C. R., Robinson, R. R., Swamy, K. S. K., McCarthy, P. J., \& Spinrad, H. 1988, ApJ, 334, 476

Osterbrock, D. E, Fullbright, J. P., Martel, A. R., Keane, M. J., Trager, S. C., \& Basri, G. 1996, PASP, 108, 277

Petek, H., Nesbitt, D. J., Darwin, D. C., \& Moore, C. B. 1987, J. Chem. Phys., 86, 1172

Phillips, J. G., \& Davis, S. P. 1968, The Swan System of the $C_{2}$ Molecule (University of California Press, Berkeley)

Ramsay, D. A., \& Winnewisser, M. 1983, Chem. Phys. Lett., 96, 502 
Rao, K. N. 1950, ApJ, 111, 306

Ross, S. C., Birss, F. W., Vervloet, M., \& Ramsay, D. A. 1988, J. Mol. Spectrosc., 129, 436

Scherb, F., Magee-Sauer, K., Roesler, F.L., \& Harlander, J. 1990, Icarus, 86, 172

III Spinrad, H. 1987, Ann. E. Astrophys., 25, 231

Suzuki, T., Saito, S., \& Hirota, E. 1983, J. Chem. Phys., 79, 1641

Tegler, S., \& Wyckoff, S. 1989, ApJ, 343, 445
Verma, R. D., \& Mulliken, R. S. 1961, Can. J. Phys, 39, 908 Vogt, S. 1987, PASP, 99, 1214

von Schmid, R., \& Gerö, L. 1935, Z. Phys., 93, 656

Weniger, S., \& Herman, R. 1958, J. Phys. Rad., 19, 582

Woodward, D. R., Fletcher, D. A., \& Brown, J. M. 1987, Mol. Phys., 62, 517.

Wyckoff, S., Tegler, S., Wehinger, P. A., Spinrad, H., \& Belton, M. J. S. 1988, ApJ, 325, 927 